\title{
Influence of the inflammatory response on treatment of hepatitis C with triple therapy
}

\author{
Fernanda Cristina Winckler ${ }^{[1]}$, Aline Marcia Marques Braz ${ }^{[2]}$, Vanessa Nogueira da Silva ${ }^{[1]}$, \\ Marjorie de Assis Golim ${ }^{[2]}$, Vanessa Gutierrez de Andrade ${ }^{[1]}$, \\ Paulo Eduardo de Abreu Machado ${ }^{[1],[2], ~ L i c i a n a ~ V a z ~ d e ~ A r r u d a ~ S i l v e i r a ~}{ }^{[3]}$ \\ and Giovanni Faria Silva ${ }^{[1]}$
}

\begin{abstract}
[1]. Departamento de Clínica Médica, Faculdade de Medicina de Botucatu, Universidade Estadual Paulista, Botucatu, SP, Brasil. [2]. Laboratório de Citometria de Fluxo, Hemocentro, Universidade Estadual Paulista, Botucatu, SP, Brasil.

[3]. Departamento de Bioestatística, Instituto de Biociências, Universidade Estadual Paulista, Botucatu, SP, Brasil.
\end{abstract}

\begin{abstract}
Introduction: Chronic hepatitis $\mathrm{C}$ is a leading cause of liver disease. Infection triggers an immediate immune response in the host that is mediated by humoral/cellular mechanisms. T cells respond to infection via secretion of cytokines, which inhibit or stimulate one another, leading to cytokine imbalance and ultimately affecting treatment. Studies using interferon (IFN) and ribavirin (RBV) showed that TCD8+ cells and cytokine levels are associated with sustainable virological response (SVR). However, studies that investigated the effects of triple therapy (TT) are limited. Methods: The study included hepatitis C virus $(\mathrm{HCV})+\mathrm{RNA}$, naives, genotype 1, $\geq 18$ years, and advanced fibrosis $(\mathrm{F} \geq 3)$ patients. Samples were collected at baseline and after 12 weeks (W12) of TT. Six cytokines were analyzed by flow cytometry. Results: Of 31 patients, four were excluded (two deaths, one interrupted TT, and one F2 patient). Of the 27 remaining patients, 21 (78\%) were cirrhotic. SVR was achieved in $63 \%$ of the patients. The patients had a mean age of $55.11 \pm 10.03$ years. Analyses at baseline showed that the chemokine CCL5/Regulated on Activation, Normal T Cell Expressed and Secreted (RANTES) ( $\mathrm{p}=0.04)$ and interleukin (IL)-6 ( $\mathrm{p}=0.02$ ), which was associated with SVR. RANTES $(\mathrm{p}=0.04)$ and IL-8 $(\mathrm{p}=0.01)$ levels were associated with SVR at W12. Conclusions: Similar to patterns observed during double therapy, IL-6, IL-8, and RANTES levels were associated with SVR in TT, indicating the potential role of interferon in immune response to hepatitis $\mathrm{C}$ virus.
\end{abstract}

Keywords: Hepatitis C. Cytokine. Treatment.

\section{INTRODUCTION}

A total of 184 million people, corresponding to $3 \%$ of the world population, are estimated to be infected with the hepatitis $\mathrm{C}$ virus ${ }^{1}$. Infection with hepatitis $\mathrm{C}$ virus is considered to be one of the major causes of liver disease and leads to the development of cirrhosis and hepatocellular carcinoma ${ }^{2}$.

Dual therapy with petylated interferon (PegIFN) and rivabirin was considered the standard treatment for chronic hepatitis C until the middle of 2011. However, low SVR rates were observed in patients with genotype 1, advanced fibrosis, and cirrhosis ${ }^{3-6}$. SVR is characterized by the absence of HCV RNA (undetected viral load or $<12 \mathrm{IU} / \mathrm{mL}$ ) by polymerase chain reaction at 24 weeks after completion of PegIFN-based therapy?

In 2011, a new class of drugs became available that included the protease inhibitors (PIs) Boceprevir and Telaprevir, which

Corresponding Author: Fernanda Cristina Winckler.

e-mail: fernanda_winckler@hotmail.com

Received 11 April 2018

Accepted 13 September 2018 were administered during TT in combination with PegIFN and RBV. Treatment with TT increased SVR rates but was not sufficiently effective, especially in patients with cirrhosis ${ }^{8,9}$. Other factors, including the IR, are associated with low SVR rates $^{10}$. Several studies have attempted to further investigate the mechanisms underlying the above findings ${ }^{11-15}$; however, the results remained ambiguous and controversial.

Infection with the hepatitis $\mathrm{C}$ virus triggers an immediate immune response in the host, which involves humoral and cellular mechanisms ${ }^{16}$.

The $\mathrm{T}$ cell response is mediated by the secretion of cytokines, which participate in a molecular cascade wherein the cytokines can stimulate or inhibit one another, eventually causing cytokine imbalance ${ }^{17,18}$. In turn, cytokine imbalance leads to sustained inflammation and the development of liver fibrosis ${ }^{19,20}$.

One study indicated that the poor response of CD4 and CD8 $\mathrm{T}$ cells observed during chronic infection could be attributed to immunological tolerance in the liver ${ }^{21}$.

Several studies showed an association between the abundance of TCD $8+$ cells and SVR ${ }^{14,22}$, and the quality of the 
Thelper (Th) 1 response in the baseline period, and the increase in Th2 cytokines during treatment may define treatment success

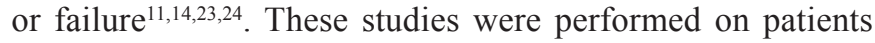
treated with dual therapy (IFN alpha or PegIFN and RBV). Regardless of the treatment response of the patient, the levels of certain cytokines and chemokines were found to be upregulated in response to stimulation by IFN. However, IFN treatment could significantly alter the host response to treatment.

The present study aimed to evaluate whether the RVS is influenced by the IR by analyzing chemokine levels in patients undergoing TT treatment.

\section{METHODS}

The prospective study was conducted at the Botucatu Medical School (FMB/UNESP) from September 1, 2014 to July 30, 2016. The study was approved by the Research Ethics Committee of the hospital.

The inclusion criteria were as follows: naive, genotype 1, fibrosis 3 or 4 (METAVIR score system ${ }^{25}$ ) patients, male and female genders, $\geq 18$ years old, candidates for TT (PIs: Boceprevir or Telaprevir), and treatment completion. Patients with hepatitis B and/or human immunodeficiency virus (HIV) co-infection, pregnant women, and users of illicit drugs and alcohol were excluded.

Samples were collected at two time points (baseline and W12 of treatment). Patients were stratified into two groups, namely, the G1 and G2 groups, according to their virologic response (G1: SVR and G2: non-SVR).

Plasma cytokine and chemokine levels [IL-6, IL-8, monocyte chemotactic protein-1 (MCP-1), RANTES, monokine induced by IFN gamma (MIG), and IFN gamma-induced protein 10 (IP-10)] were quantified at two time points of treatment. Comparative analyses were performed by evaluating the cytokine and chemokine levels between the two groups at the same time point $(\mathrm{G} 1 \times \mathrm{G} 2-$ baseline; $\mathrm{G} 1 \times \mathrm{G} 2-\mathrm{W} 12)$ and between the two treatment points within the same group (G1 baseline $\times$ W12; G2 - baseline $\times$ W12).
Statistical tests were performed using SAS software version 4.0 for Windows. $\mathrm{P}<0.05$ was considered statistically significant. Fisher's exact test was used for association analyses. The Kruskal-Wallis nonparametric test was used to compare the variables when the data did not satisfy normality assumptions.

For sample collection, venous blood was placed in two tubes containing ethylenediamine tetraacetic acid (EDTA) (5 ml each). Samples were centrifuged for $10 \mathrm{~min}$ at $300 \mathrm{~g}$, and aliquots of plasma were placed in Eppendorf $₫$ microtubes and subsequently frozen at $-80^{\circ} \mathrm{C}$.

Cytokine and chemokine levels were analyzed by flow cytometry following the CBA method using the kits CBA Human Chemokine (MCP-1, RANTES, IL-8, MIG, and IP-10) and Human IL-6 Flex Set.

Data were collected after obtaining informed consent from the patients. Informed consent was additionally obtained from a patient's legally authorized representative when the patient could not consent. The procedures were conducted in accordance with the Helsinki Declaration of 1975, which was revised in 1983. The present study was approved by the Ethics Committee of the Botucatu Medical School (Approval number of the ethics committee: 773.353).

\section{RESULTS}

A total of 31 patients were screened, out of which four were excluded because of the following reasons: two deaths, one interrupted treatment, and one patient was assigned to the F2 stage based on the METAVIR score.

Of the 27 remaining patients, $78 \%$ (21) were cirrhotic. The majority of patients were male (67\%). The average age of the patients was $55.11 \pm 10.03$. SVR, F4, and F3 were observed in $63 \%, 57 \%(12 / 21)$, and $83 \%(5 / 6)$ of all patients.

Results from the analysis of cytokine and chemokine levels in the TT baseline period (G1 vs. G2) are presented in Table 1. RANTES ( $\mathrm{p}=0.04)$ and IL-6 ( $\mathrm{p}=0.02$ ) levels were found to be associated with SVR, and downregulation of both parameters was observed in the SVR group.

TABLE 1: Comparison of cytokine and chemokine levels between SVR and non-SVR patients undergoing triple therapy at the baseline period.

\begin{tabular}{cccc}
\hline Variable $(\mathbf{n = 2 7})$ & SVR $(\mathbf{n = 1 7})$ & Non-SVR $(\mathbf{n = 1 0})$ & P-value \\
\hline IP10 & $723.36(601.00-1240.25)$ & $1048.80(752.30-1502.66)$ & 0.37 \\
MCP-1 & $24.95(19.18-51.72)$ & $39.34(18.54-51.20)$ & 0.76 \\
MIG & $335.48(200.21-574.72)$ & $336.02(167.17-564.08)$ & 0.76 \\
RANTES & $2306.08(1629.33-2524.76)$ & $2777.48(2340.67-3440.24)$ & $0.04^{*}$ \\
IL8 & $15.02(5.97-21.61)$ & $21.10(11.78-40.10)$ & 0.12 \\
IL6 & $0(0-0)$ & $0.29(0-4.61)$ & $0.02^{*}$
\end{tabular}

SVR: virological response. Interleukin (IL)-6, IL-8, regulated on activation normal T cell expressed and secreted (RANTES), monocyte chemotactic protein-1 (MCP-1), monokine induced by gamma IFN (MIG) and IFN gamma-induced protein 10 (IP-10). Results are expressed as a median and interquartile range (25; 75 ). 
Table 2 shows the comparison of cytokine and chemokine levels between the G1 and G2 groups at the W12 time point. RANTES $(p=0.04)$ and IL-8 $(p=0.01)$ levels were downregulated in the G1 group, and the observed differences were significantly associated with SVR. Expression levels of other cytokines and chemokines were not associated with SVR, although some parameters were higher in the non SVR group.

Table 3 and Table 4 show the comparison between the baseline and W12 time points in the G1 and G2 groups, respectively.

Table 3 (G1) shows significant differences in the plasma levels of IL-6 $(p=0.02)$ and MCP-1 $(p=0.001)$ between the two different time points. Both treatment groups showed the upregulation of IL-6 and MCP-1 levels at W12. Although other parameters showed similar patterns, the observed differences did not reach statistical significance. RANTES was the only parameter that was downregulated at $\mathrm{W} 12$ relative to $\mathrm{W} 0$; however, the observed difference was not statistically significant.

As shown in Table 4, the RANTES ( $p=0.05$ ) and MCP-1 $(p=0.01)$ levels were significantly different between the baseline and W12 time points in the G2 group. Although the other cytokines and chemokines showed no significant differences between the two time points, an increase in W12 levels occurs

\section{DISCUSSION}

Elucidating the mechanisms underlying IR during the different treatment regimens for $\mathrm{HCV}$ is of great importance because the SVR is influenced by the host IR, as previously established by studies on patients undergoing dual therapy ${ }^{14,17,21,26}$. In particular, previous findings indicated that the production of cytokines and chemokines plays an important role in the IR during HCV infection. However, there is limited knowledge on the IR during TT. Thus, there is a need to investigate whether the addition of PIs to PegIFN/RBV treatment alters cytokine and chemokine profiles and whether the induced changes enhance the host's response to the treatment.

Our results showed that circulating levels of RANTES and IL-6 at the baseline period were associated with SVR (Table 1). Patients who did not achieve SVR presented higher

TABLE 2: Analysis of cytokine and chemokine levels between SVR and non-SVR patients undergoing triple therapy at W12.

\begin{tabular}{cccc}
\hline Variable $(\mathbf{n = 2 7})$ & SVR $(\mathbf{n = 1 7 )}$ & Non-SVR $(\mathbf{n}=\mathbf{1 0})$ & P value \\
\hline IP10 & $764.25(557.09-980.73)$ & $1029.90(610.24-1476.23)$ & 0.34 \\
MCP-1 & $63.94(53.29-121-87)$ & $78.12(50.69-119.01)$ & 0.96 \\
MIG & $421.51(266.19-872.92)$ & $410.83(225.43-499.41)$ & 0.58 \\
RANTES & $2239.00(1629.33-3756.25)$ & $4003.89(3381.49-4698-48)$ & $0.04^{*}$ \\
IL8 & $19.17(11.58-30.41)$ & $37.20(23.04-56.83)$ & $0.01^{*}$ \\
IL6 & $0(0-3.46)$ & $2.19(0-8.78)$ & 0.59 \\
\hline
\end{tabular}

SVR: virological response. Interleukin (IL)-6, IL-8, regulated on activation normal T cell expressed and secreted (RANTES), monocyte chemotactic protein-1 (MCP-1), monokine induced by gamma IFN (MIG) and IFN gamma-induced protein 10 (IP-10). Results are expressed as a median and interquartile range (25; 75)

TABLE 3: Analysis of cytokine and chemokine levels in SVR patients at baseline and W12.

\begin{tabular}{cccc}
\hline Variable $(\mathbf{n = 2 7})$ & Week 0 & Week 12 & P value \\
\hline IP10 & $723.36(601.00-1240.25)$ & $764.25(557.09-980.73)$ & 0.89 \\
MCP-1 & $24.95(19.18-51.72)$ & $63.94(53.29-121-87)$ & $0.001^{*}$ \\
MIG & $335.48(200.21-574.72)$ & $421.51(266.19-872.92)$ & 0.36 \\
RANTES & $2306.08(1629.33-2524.76)$ & $2239.00(1629.33-3756.25)$ & 0.38 \\
IL8 & $15.02(5.97-21.61)$ & $19.17(11.58-30.41)$ & 0.26 \\
IL6 & $0(0-0)$ & $0(0-3.46)$ & $0.02^{*}$ \\
\hline
\end{tabular}

SVR: virological response. Interleukin (IL)-6, IL-8, regulated on activation normal T cell expressed and secreted (RANTES), monocyte chemotactic protein-1 (MCP-1), monokine induced by gamma IFN (MIG) and IFN gamma-induced protein 10 (IP-10). Results are expressed as a median and interquartile range (25; 75).

TABLE 4: Analysis of cytokine and chemokine levels in non-SVR patients at baseline and W12.

\begin{tabular}{ccc}
\hline Variable $(\mathbf{n = 2 7})$ & Week 0 & Week 12 \\
\hline IP10 & $1048.80(752.30-1502.66)$ & $1029.90(610.24-1476.23)$ \\
MCP-1 & $39.34(18.54-51.20)$ & $78.12(50.69-119.01)$ \\
MIG & $336.02(167.17-564.08)$ & $410.83(225.43-499.41)$ \\
RANTES & $2777.48(2340.67-3440.24)$ & $4003.89(3381.49-4698-48)$ \\
IL8 & $21.10(11.78-40.10)$ & $37.20(23.04-56.83)$ \\
IL6 & $0.29(0-4.61)$ & 0.62 \\
\hline
\end{tabular}

Interleukin (IL)-6, IL-8, regulated on activation normal T cell expressed and secreted (RANTES), monocyte chemotactic protein-1 (MCP-1), monokine induced by gamma IFN (MIG) and IFN gamma-induced protein 10 (IP-10). Results are expressed as a median and interquartile range (25; 75). 
IL-6 levels than those in the RVS group. Therefore, our findings were consistent with previous studies showing that the cytokine levels were associated with double therapy and that IFN influenced cytokine behavior ${ }^{27,28}$. Lower baseline RANTES levels were observed in the RVS group (Table 1), consistent with the findings reported in an independent study that investigated patients who received dual therapy ${ }^{29}$. However, another study ${ }^{30}$ reported that high RANTES levels at baseline were associated with SVR in dual therapy in patients with low fibrosis $(\mathrm{F} \leq 2)$. On the other hand, our subjects included $78 \%$ cirrhotic patients and $22 \%$ advanced fibrosis patients.

Our current findings showed that patients with higher levels of IP-10 at baseline did not reach SVR and were not associated with SVR. Nevertheless, some studies indicated that low serum levels of IP-10 at baseline were associated with SVR during dual therapy ${ }^{31-34}$.

Baseline IL-8 levels were higher in the non-SVR group compared to those in the SVR group, but the differences did not reach statistical significance. Studies have shown that increased serum IL-8 levels were associated with non-response to IFN-based treatment and disease progression ${ }^{35,36}$.

Table 2 shows the analysis of IL-8 and RANTES levels with SVR at W12. The patient group with lower IL-8 levels reached SVR.

The chemokine IL-8 is an important member of the chemokine CXC family. The key function of IL-8 is to attract polymorphonuclear cells to sites of tissue injury and inflammation. IL-8 is synthesized by several cell types, including monocytes, macrophages, Kupffer cells, hepatocytes, and hepatic stellate cells ${ }^{35-37}$. IL-8 levels are upregulated in the peripheral blood and liver, thereby indicating that increased tissue infiltration and macrophage-induced hepatic activation are mediated by the interaction between IL- 8 and CXCR-1 during hepatitis $\mathrm{C}$ infection ${ }^{35}$.

RANTES levels were found to be associated with SVR in W12 (Table 2), similar to baseline levels (Table 1). These results were contradictory to those of a previous study on patients undergoing dual therapy, ${ }^{29}$ in which RANTES levels were not associated with SVR, although RANTES levels were upregulated during treatment in patients who did not achieve SVR. Multiple studies reported different effects of IFN- $\alpha$ on RANTES expression in different cell types ${ }^{38,39}$.

More recently, two studies on patients subjected to TT evaluated the influence and behavior of IP-10 chemokines in SVR. One study evaluated 15 patients at different time points during the treatment period and did not identify differences in IP-10 chemokine levels between the SVR and non-SVR groups ${ }^{40}$. Another study evaluated 97 patients at baseline and showed that IP-10 levels were associated with SVR ${ }^{41}$. Our results showed no association between IP-10 and SVR in any of the evaluated time points. However, patients in the SVR group were observed to have lower IP-10 levels at both time points. Analysis of a larger sample size are likely to reproduce the above findings.

Median cytokine levels of patients in the SVR group were evaluated at baseline and W12 (Table 3). Notably, MCP-1 and
IL-6 levels were significantly different between the two time points. A previous study assessed HIV co-infected patients and observed that high IL-6 levels were associated with therapeutic failure with IFN- $\alpha^{42}$. Another study showed that IL-6 levels were decreased during IFN- $\alpha$ treatment in patients who reached SVR. Similar changes were observed among non-SVR patients, although IL-6 levels were restored at the end of the dual treatment ${ }^{43}$.

MCP-1 chemokines are known to play roles in the chemotactic recruitment of monocytes. Our current results showed that MCP-1 levels were upregulated with the independent response found in TT during treatment (Table 3 and Table 4). A previous study reported similar findings during dual therapy treatment. ${ }^{44}$ However, another study ${ }^{45}$ indicated that the same pattern was observed only in SVR patients.

Table 4 compares the variables in the non-SVR group between the baseline and W12. Both MCP-1 and RANTES levels were significantly different between the two time points.

The chemokine RANTES was found to be significantly upregulated during treatment in the non-SVR group (Table 4) at the baseline and W12 time points. In accordance with a previous study, the observed increase in RANTES levels was associated with the presence of inflammation. The hepatitis $\mathrm{C}$ virus induces RANTES production by macrophages ${ }^{46}$. Evidence suggests that IFN type I inhibits the production of RANTES by T cells ${ }^{47}$. Therefore, consistent with the expected results, RANTES levels did not increase during TT treatment in the SVR group (Table 3).

A previous study that assessed cytokine and chemokine levels during dual therapy treatment showed that IL-8 levels were lower throughout the treatment and were associated with $\mathrm{SVR}^{48}$. In contrast to the abovementioned findings, our current results indicated that IL-8 levels were upregulated during the early periods of TT treatment in both patient groups (Table 3 and Table 4).

In a previous study on patients undergoing dual therapy, ${ }^{49}$ levels of the cytokine MIG were shown to be downregulated during SVR. By contrast, our results showed that the MIG levels were upregulated in both groups (Table 3 and 4); however, the SVR group presented higher MIG levels at W12, although the differences were also not significant (Table 2). Moura et al. (2011) investigated subjects undergoing dual therapy and showed that patients in the SVR group had higher MIG levels than those in the non-SVR group; however, the differences were not statistically significant.

\section{CONCLUSION}

Our findings showed that RANTES, IL-6, and IL-8 levels were associated with SVR during TT treatment. Our results were similar to those observed in patients with double therapy, thereby supporting the role of IFN in the host RI. Further studies are required to investigate the cytokine and chemokine profiles under treatment with currently available IFN-free drugs, which consequently induce different immunological and virologic mechanisms without the interference of IFN. 


\section{Conflict of interest}

The authors declare that there is no conflict of interest.

\section{REFERENCES}

1. World Health Organization (WHO). Guidelines for the screening, care and treatment of persons with hepatitis $\mathrm{C}$ infection. Geneva: WHO; 2014. 124 p.

2. Gower E, Estes C, Blach S, Razavi-Shearer K, Razavi H. Global epidemiology and genotype distribution of the hepatitis $\mathrm{C}$ virus infection. J Hepatol. 2014;61(Suppl 1):S45-57.

3. Manss MP, McHutchison JG, Gordon SC, Rustgi VK, Shiffman $\mathrm{M}$, Reindollar R, et al. Peginterferon alfa- $2 \mathrm{~b}$ plus ribavirin compared with interferon alfa- $2 \mathrm{~b}$ plus ribavirin for initial treatment of chronic hepatitis C: a randomised trial. Lancet. 2001;358(9286):958-65.

4. Bruno S, Shiffman ML, Roberts SK, Gane EJ, Messinger D, Hadziyannis SJ, et al. Efficacy and Safety of Peginterferon Alfa2a (40KD) Plus Ribavirin in Hepatitis C Patients with Advanced Fibrosis and Cirrhosis. Hepatology. 2010;51(2):388-97.

5. Silva GF, Polônio RJ, Pardini MI, Corvino SM, Henriques RM, Peres $\mathrm{MN}$, et al. Using Pegylated Interferon alfa-2b and Ribavirin to Treat Chronic Hepatitis Patients Infected with Hepatitis C Virus Genotype 1: Are Nonresponders and Relapsers Different Populations? Braz J Infect Dis 2007;11(6):554-60.

6. Silva GF, Villela-Nogueira CA, Mello CE, Soares EC, Coelho HS, Ferreira PR, et al. Peginterferon plus ribavirin and sustained virological response rate in HCV-related advanced fibrosis: a real life study. Braz J Infect Dis. 2014;18(1):48-52.

7. Martinot-Peignoux M, Stern C, Maylin S, Ripault MP, Boyer $\mathrm{N}$, Leclere L, et al. Twelve weeks posttreatment follow-up is as relevant as 24 weeks to determine the sustained virologic response in patients with hepatitis $\mathrm{C}$ virus receiving pegylated interferon and ribavirin. Hepatology. 2010;51(4):1122-6.

8. Bacon BR, Gordon SC, Lawitz E, Marcellin P, Vierling JM, Zeuzem S, et al. Boceprevir for Previously Treated Chronic HCV Genotype 1 Infection. N Engl J Med. 2011;364(13):1207-17.

9. Zeuzem S, Andreone P, Pol S, Lawitz E, Diago M, Roberts S, et al. Telaprevir for retreatment of HCV infection. $N$ Engl $J$ Med. 2011;364(25):2417-28.

10. Edlich B, Ahlenstiel G, Azpiroz AZ, Stoltzfus J, Noureddin M, Serti E, et al. Early changes in interferon signaling define natural killer cell response and refractoriness to interferon-based therapy of hepatitis C. Hepatology. 2012;55(1):39-48.

11. Moura AS, Carmo RA, Teixeira AL, Teixeira MM, Rocha MO. Soluble inflammatory markers as predictors of virological response in patients with chronic hepatitis $\mathrm{C}$ virus infection treated with interferon- $\alpha$ plus ribavirin. Mem Inst Oswaldo Cruz. 2011;106(1):38-43.

12. Komase K, Maekawa S, Miura M, Sueki R, Kadokura M, Shindo $\mathrm{H}$, et al. Serum RANTES level influences the response to pegylated interferon and ribarivin therapy in chronic hepatitis C. Hepatol Res. 2013,43(8):865-75.

13. Zeremski M, Petrovic LM, Talal AH. The role of chemokines as inflammatory mediators in chronic hepatitis $\mathrm{C}$ virus infection. J Viral Hepat. 2007;14(10):675-87.

14. Nguyen TT, Niloofar R, Rubbo PA, Nils K, Bollore K, Ducos J, et al. Cytokine Response Associated with Hepatitis C Virus Clearance in HIV Coinfected Patients Initiating Peg Interferon- $\alpha$ Based Therapy. Mediterr J Hematol Infec Dis. 2016;8(1):e2016003.

15. Wandrer F, Falk CS, John K, Skawran B, Manns MP, SchulzeOsthoff $\mathrm{K}$, et al. Interferon-Mediated Cytokine Induction
Determines Sustained Virus Control in Chronic Hepatitis C Virus Infection. J Infect Dis. 2016;213(5):746-54.

16. Barbosa KVBD, Teixeira R, Bassetti-Soares E, de Souza AF, Penido JM, Teixeira-Carvalho A, et al. Phenotypic features of innate and adaptive immunity in patients with chronic hepatitis $\mathrm{C}$ and endstage renal disease. Liver Int. 2013;33(9):1349-56.

17. Amati L, Caradonna L, Magrone T, Mastronardi ML, Cuppone R, Cozzolongo R, et al. Modifications of the Immune Responsiveness in Patients with Hepatitis C Virus Infection following Treatment with IFN-a / Ribavirin. Curr Pharm Des. 2002;8(11):981-93.

18. Nelson DR, Tu Z, Soldevila-Pico C, Abdelmalek M, Zhu H, Xu $\mathrm{YL}$, et al. Long-term Interleukin 10 therapy in chronic hepatitis $\mathrm{C}$ patients has a proviral and anti-inflammatory effect. Hepatolology. 2003;38(4):859-69.

19. Jacobson-Brown PM, Neuman MG. Immunopathogenesis of hepatitis $\mathrm{C}$ virus infection: Th1/Th2 responses and the role of cytokines. Clin Biochem. 2001;34(3):167-71.

20. Neuman MG, Schmilovitz-Weiss H, Hilzenrat N, Bourliere M, Marcellin P, Trepo C, et al. Markers of inflammation and fibrosis in alcoholic hepatitis and viral hepatitis C. Int J Hepatol. 2012;2012:231210.

21. Fathy A, Ahmed AS, Metwally L, Hassan A. T helper type 1/T helper type 17-related cytokines in chronic hepatitis $\mathrm{C}$ patients before and after interferon and ribavirin therapy. Med Princ Pract. 2011;20(4):345-9.

22. Araujo AR, Peruhype-Magalhães V, Coelho-dos-Reis JG, Chaves LP, de Lima TA, Pimentel JP, et al. Dual role of IL-12 in the therapeutic efficacy or failure during combined PEG-Interferon$\alpha 2 \mathrm{~A}$ and ribavirin therapy in patients with chronic hepatitis $\mathrm{C}$. Immunol Lett. 2013;154(1-2):61-9.

23. Falconer K, Askarieh G, Weis N, Hellstrand K, Alaeus A, Lagging M. IP-10 predicts the first phase decline of HCV RNA and overall viral response to therapy in patients co-infected with chronic hepatitis C virus infection and HIV. Scand J Infect Dis. 2010;42(1112):896-901.

24. Fujimoto T, Tomimatsu M, Iga D, Endo H, Otsuka KJ. Changes in the Th1/Th2 ratio during a 24 -week course of an interferon alpha$2 \mathrm{~b}$ plus ribavirin combination therapy for patients with chronic hepatitis C. J Gastroenterol Hepatol. 2008;23(8Pt2);e432-7.

25. Bedossa P, Poynard T. An algorithm for the grading of activity in chronic hepatitis C. The METAVIR Cooperative study Group. Hepatology. 1996;24(2):289-93.

26. Tarragô AM, Costa AG, Pimentel JPD, Gomes STM, Freitas FB, Lalwani $\mathrm{P}$, et al. Combined impact of hepatitis $\mathrm{C}$ virus genotype 1 and interleukin- 6 and tumor necrosis factor-a polymorphisms on serum levels of pro-inflammatory cytokines in Brazilian HCVinfected patients. Hum Immunol. 2014;75(11):1075-83.

27. Gao B, Hong F, Radaeva S. Host factors and failure of interferonalfa treatment in HCV. Hepatology. 2004;39(4):880-90.

28. Pavon-Castillero EJ, Munoz-de-Rueda P, Lopez-Segura R, Gila A, Quiles R, Munoz-Gamez JA, et al. Importance of IL-10 and IL-6 during chronic hepatitis $\mathrm{C}$ genotype-1 treatment and their relation with IL28B. Cytokine. 2013;61(2):595-601.

29. Yoneda S, Umemura T, Joshita S, Ichijo T, Matsumoto A, Yoshizawa $\mathrm{K}$, et al. Serum chemokine levels are associated with the outcome of pegylated interferon and ribavirin therapy in patients with chronic hepatitis C. Hepatol Res. 2011;41(6):587-93.

30. Katsounas A, Trippler M, Wang B, Polis M, Lempicki RA, Kottilil $\mathrm{S}$, et al. CCL5 mRNA is a Marker for early fibrosis in chronic hepatitis $\mathrm{C}$ and is regulated by Interferon- $\alpha$ therapy and Toll-like receptor 3 signaling. J Viral Hepat. 2012;19(2):128-37. 
31. Diago M, Castellano G, Garcia-Samaniego J, Pérez C, Fernández I, Romero H, et al. Association of pretreatment serum interferon $\gamma$ inducible protein 10 levels with sustained virological response to peginterferon plus ribavirin therapy in genotype 1 infected patients with chronic hepatitis C. Gut. 2006;55(3):374-9.

32. Moura AS, Carmo RA, Teixeira AL, Rocha MO. Soluble inflammatory markers as predictors of hepatocellular damage and therapeutic response in chronic hepatitis C. Braz J Infect Dis. 2009;13(5):375-82.

33. Larrubia JR, Benito-Martínez S, Calvino M, Sanz-de-Villalobos E, Parra-Cid T. Role of chemokines and their receptors in viral persistence and liver damage during chronic hepatites $\mathrm{C}$ vírus infection. World J Gastroenterol. 2008;14(47):7149-59.

34. Willemse SB, Reesink HW, Ladee K, Karlas J, Gelderblom HC, Molenkamp R, et al. IP-10 in chronic hepatitis C patients treated with high-dose interferon. Neth. J Med. 2014;72(8):407-15.

35. Zimmermann HW, Seidler S, Gassler N, Nattermann J, Luedde $\mathrm{t}$, Trautwein C, et al. Interleukin-8 Is Activated in Patients with Chronic Liver Diseases and Associated with Hepatic Macrophage Accumulation in Human Liver Fibrosis. PLoS One. 2011;6(6):e21381.

36. Polyak SJ, Khabar KS, Rezeiq M, Gretch DR. Elevated levels of interleukin- 8 in serum are associated with hepatitis $\mathrm{C}$ virus infection and resistance to interferon therapy. J Virol. 2001;75(13):6209-11.

37. Huang YS, Chan CY, Wu JC, Pai CH, Chao Y, Lee SD. Serum levels of interleukin-8 in alcoholic liver disease: relationship with disease stage, biochemical parameters and survival. J Hepatol. 1996;24(4):377-84

38. Cremer I, Ghysdael J, Vieillard V. A non-classical ISRE/ISGF3 pathway mediates induction of RANTES gene transcription by type I IFNs. FEBS Lett. 2002;511(1-3):41-5.

39. Zimmerer JM, Lesinski GB, Radmacher MD, Ruppert A, Carson III WE. STAT1-dependent and STAT1-independent gene expression in murine immune cells following stimulation with interferon-alpha. Cancer Immunol Immunother. 2007;56(11):1845-52.

40. Zeremski M, Dimova RB, Benjamin S, Penney MS, Botfield MC, Talal AH. Intrahepatic and Peripheral CXCL10 Expression in Hepatitis C Virus-Infected Patients Treated With Telaprevir, Pegylated Interferon, and Ribavirin. J Infect Dis. 2015;211(11): 1795-9.
41. Nishikawa H, Enomoto H, Nasu A, Aizawa N, Saito M, Tamori A, et al. Clinical significance of pretreatment serum interferongamma-inducible protein 10 concentrations in chronic hepatitis $\mathrm{C}$ patients treated with telaprevir-based triple therapy. Hepatol Res. 2014;44(14):E397-407.

42. Guzman-Fulgencio M, Jimenez JL, Berenguer J, FernandezRodriguez A, Lopez JC, Cosin J, et al. Plasma IL-6 and IL-9 predict the failure of interferon-alpha plus ribavirin therapy in HIV/HCVcoinfected patients. J Antimicrob Chemother. 2012; 67(5):1238-45.

43. Grungreiff K, Reinhold D, Ansorge S. Serum concentrations of sIL-2R, IL-6, TGF-beta1, neopterin, and zinc in chronic hepatitis C patients treated with interferon-alpha. Cytokine. 1999;11(12):107680 .

44. Florholmen J, Kristiansen MG, Steigen SE, Sørbye SW, Paulssen EJ, Kvamme JM, et al. A rapid chemokine response of macrophage inflammatory protein (MIP)-1a, MIP-1b and the regulated on activation, normal $\mathrm{T}$ expressed and secreted chemokine is associated with a sustained virological response in the treatment of chronic hepatitis C. Clin Microbiol Infect. 2011;17(2):204-9.

45. Kushner L, Wendelboe AM, Lazzeroni LC, Chary A, Winters MA, Osinusi A, et al. Immune biomarker differences and changes comparing HCV mono-infected, HIV/HCV co-infected, and HCV spontaneously cleared patients. PLoS One. 2013;8(4):e60387.

46. Sasaki R, Devhare PB, Steele R, Ray R, Ray RB. Hepatitis C virus induced CCL5 secretion from macrophages activates hepatic stellate cells. Hepatology. 2017; 66(3):746-57.

47. Zang YC, Halder JB, Samanta AK, Hong J, Rivera VM, Zhang JZ. Regulation of chemokine receptor CCR5 and production of RANTES and MIP-1alpha by interferon-beta. J Neuroimmunol. 2001;112(1-2):174-80.

48. Alhetheel A, Albarrag A, Shakoor Z, Alswat K, Abdo A, AlHamoudi W. Assessment of pro-inflammatory cytokines in sera of patients with hepatitis $\mathrm{C}$ virus infection before and after anti-viral therapy. J Infect Dev Ctries. 2016;10(10):1093-8.

49. Butera D, Marukian S, Iwamaye AE, Hembrador E, Chambers TJ, Di Bisceglie, AM, et al. Plasma chemokine levels correlate with the outcome of antiviral therapy in patients with hepatitis C. Blood. 2005;106(4):1175-82. 